\title{
Modified supracricoid laryngectomy: oncological and functional outcomes in the elderly
}

\author{
This article was published in the following Dove Press journal: \\ Clinical Interventions in Aging \\ 7 November 2012 \\ Number of times this article has been viewed
}

\section{Eugenia Allegra \\ Teresa Franco \\ Serena Trapasso \\ Rossana Domanico \\ Alessandro La Boria \\ Aldo Garozzo \\ Department of Otolaryngology- Head and Neck Surgery, University of Catanzaro, Catanzaro, Italy}

Correspondence: Eugenia Allegra Unità Operativa di Otorinolaringoiatria, Campus Universitario "S.Venuta" Germaneto Catanzaro, Università "Magna Graecia", Viale Europa-Località Germaneto, 88I00 Catanzaro, Italy

Tel +39096 I364 7|30

Fax +39 096 |364 7|3|

Email eualle@unicz.it
Background: Supracricoid laryngectomy is an organ preservation surgical technique for early-stage glottic tumors. Modified supracricoid laryngectomy using sternohyoid muscles for neoglottis reconstruction is a new surgical technique. This report evaluates oncological and functional outcomes of this new technique and its feasibility in elderly patients.

Methods: Clinical records from 21 consecutive patients affected by glottic cancer and treated by modified SCL between 2004 and 2009 were retrospectively reviewed. Postoperative parameters and quality of voice after modified SCL were retrospectively reviewed. Actuarial overall survival, disease-specific survival rates, and recurrence-free survival rates were assessed. The functional and oncological outcomes of patients over 65 years were compared with those of patients younger than 65 years of age.

Results: There were no postoperative complications and all of the patients had complete swallowing rehabilitation. Twenty of the 21 patients had decannulation. Two patients received total laryngectomy for locoregional relapse. Overall survival and disease-specific survival rates were $100 \%$. Recurrence-free survival rates were $90.1 \%$ and $90 \%$ in patients younger and older than 65 years of age, respectively. The larynx preservation index was lower in patients who were older than 65 years of age. The postoperative courses with regard to functional outcome and voice quality in elderly patients were similar to those of patients younger than 65 years of age.

Conclusion: Modified SCL is a new open organ preservation surgical technique that is oncologically safe. The positive functional and oncological outcomes of this surgical procedure allow it to be performed in elderly patients.

Keywords: supracricoid laryngectomy, modified, early glottic cancer, cricohyoidoepiglottopexy, cricohyoidopexy, elderly, larynx, cancer

\section{Introduction}

Early glottic cancers are treated with the intent of preserving the larynx and its functions. ${ }^{1}$ Majer and Rieder ${ }^{2}$ introduced supracricoid laryngectomy (SCL) in 1959 as a new partial laryngectomy that restored laryngeal function in patients with early glottic cancer. SCL is widely used in Europe and has reduced the indications for total laryngectomy. Recent reports ${ }^{3-5}$ indicate that SCL has also been applied in selected advanced laryngeal cancer and after radiotherapy failure.

Garozzo et $\mathrm{al}^{6}$ introduced an SCL variant using sternohyoid muscles for neoglottis reconstruction. This innovative technique recreates anatomical conditions and produces more efficient lateral-medial movement of the arytenoids. Modified SCL can be performed in both cricohyoidopexy (CHP) and cricohyoidoepiglottopexy (CHEP) modalities. Previously reported functional results show significant improvements in 
quality of life and quality of voice, especially in comparison with the functional outcomes of the original SCL technique. ${ }^{7,8}$ According to recent reports, ${ }^{9}$ elderly patients with early larynx cancer can be treated with curative intent by partial laryngectomies. Therefore, we performed modified SCL in patients older than 65 years of age. Oncological and functional outcomes were retrospectively reviewed and compared between patients younger and older than 65 years of age, to assess the reliability of modified SCL in elderly patients.

\section{Materials and methods}

A retrospective review of clinical records from 21 consecutive patients affected by Stage I-III glottic squamous cell carcinoma and treated by modified SCL between January 2004 and December 2009 (19 SCL modified with CHEP and two SCL modified with CHP) was performed.

The mean age of the patients was 61.2 (range 43-75) years; 10 patients were older than 65 years of age (mean $70.5 \pm 3.4$ years) and 11 were younger than 65 years $(53.0 \pm 7.3$ years, $P<0.001)$. The only woman in the sample was in the younger patient group. Karnofsky performance status was $100 \%$ in eight of the patients younger than 65 years of age, and $90 \%$ in the remaining three patients younger than 65 years of age, $90 \%$ in four of the patients older than 65 years of age, $80 \%$ in five patients older than 65 years of age, and $70 \%$ in one patient older than 65 years of age.

All patients had a laryngeal biopsy before modified SCL and the stage was determined by videolaryngoscopy, neck ultrasound, and contrast whole body computed tomography, in accordance with the staging protocol of our department. All patients had glottic cancer. The stage was determined in accordance with the 7 th edition of the TNM classification established by the American Joint Committee for Cancer, ${ }^{10}$ as T1bN0M0 in six patients, T2N0M0 in 12 patients, T3N0M0 in one patient, T1bN1M0 in one patient, and T2N2bM0 in one patient.

Modified SCL was indicated in patients with T1b, T2-T3 glottic cancer, in which both arytenoids are movable, who had not received previous chemoradiotherapy. Modified SCL was performed as previously described; ${ }^{6}$ sternohyoid muscles of both sides were detached from the hyoid bone, leaving inferior vascularization. They were individually fashioned into a tubular shape and placed on the free margin of the cricoid, anchored to the vocal apophysis of the arytenoids, and covered by the redundant mucosa overlying the arytenoids. The neolarynx was closed by three sutures, ie, one to the anterior midline and one lateral to the muscle flap on each side.
The modified SCL variant with CHP or CHEP was selected according to tumor localization and extension. Nineteen patients received modified SCL-CHEP and two patients received modified SCL-CHP. Modified SCL-CHEP was associated with monolateral selective neck dissection in two patients, and in both cases, nodes were negative at histological examination. All surgical margins were negative and none of the patients received adjuvant chemoradiotherapy. Modified SCL was always performed by the same surgical team.

Postoperative outcomes, functional results, and follow-up were retrospectively reviewed. Patients were followed up every 3 months for the first year, every 6 months for the next 3 years, and every 12 months thereafter. Follow-up visits included clinical examination, laryngoscopy, and radiological examinations, including neck ultrasound, chest $\mathrm{x}$-ray, and total body tomography or magnetic resonance imaging, according to clinical evidence.

Oncological outcomes were assessed for actuarial overall survival rate, actuarial disease-specific free survival and actuarial recurrence-free survival rate by the Kaplan-Meier method, and laryngoesophageal dysfunction-free survival. ${ }^{17}$ The larynx preservation index was assessed as the percentage of patients maintaining both the larynx and laryngeal function. The histopathological status of the thyroid cartilage was recorded and compared with the clinical characteristics of tumors to evaluate the oncological safety and radicality of modified SCL.

Voice quality was evaluated 6 months after surgery using the INFVo rating scale proposed by Moerman et al ${ }^{11}$ for substitution voices. This scale comprises four items, ie, intelligibility, noise, fluency, and voicing. Each item is scored on a 10-point rating scale, with 0 representing poor voice quality and 10 representing good quality. A final score was calculated for each patient as the mean score derived from evaluations of two otolaryngologists (RD, ALB) and two speech therapists. The normal voice score for the four items on the INFVo scale was 40 . We classified voice quality levels $>28$ as good, 24-28 as fair, and $<24$ as poor. INFVo scores were compared between the two groups of patients.

The study was approved by the institutional review board of Magna Graecia University of Catanzaro, Italy. Statistical analysis by $\chi^{2}$, Fisher's Exact, and Mann-Whitney tests were used to identify statistically significant differences in functional and oncological outcomes between the two groups of patients. The significance level was set at $P<0.05$. All analyses were performed using a commercially available software program (MedCalc Software, version 12.2.1, Mariakerke, Belgium). 


\section{Results}

Data concerning demographic characteristics, tumor stage, and surgery are reported in Table 1. Data concerning postoperative outcomes, functional results, and follow-up are reported in Table 2. Length of hospitalization and nasogastric feeding tube removal time were $23.3 \pm 6.2$ (range 14-43) days and 13.9 \pm 1.7 (range 11-16) days, respectively. There were no postoperative complications and all patients were discharged in good condition. The length of hospitalization was similar in patients younger than 65 years of age (22.6 \pm 5.4 days) and in patients older than 65 years of age (24.1 \pm 7.2 days; $P=0.60$ ). Nasogastric feeding tube removal occurred $13.9 \pm 1.9$ days after modified SCL in patients younger than 65 years of age and $13.9 \pm 1.5$ days in patients older than 65 years of age, with no statistically significant difference $(P=0.99)$.

All of the patients had complete swallowing rehabilitation and none received gastrostomy. Twenty (95.2\%) of the 21 patients had decannulation; all patients younger than 65 years of age and nine of the 10 patients $(90 \%)$ older than 65 years of age had decannulation (one patient developed a recurrence of disease after a period of time, hence underwent

Table I Demographic characteristics, tumor staging, and surgical treatment

\begin{tabular}{|c|c|c|c|}
\hline Parameter & $\begin{array}{l}\text { Patients } \\
(n=2 I)\end{array}$ & $\begin{array}{l}\text { Patients } \\
<65 \text { years } \\
(\mathrm{n}=\mathrm{II})\end{array}$ & $\begin{array}{l}\text { Patients } \\
>65 \text { years } \\
(n=10)\end{array}$ \\
\hline Patients, n (\%) & $21(100)$ & II (52.4) & $10(47.6)$ \\
\hline \multicolumn{4}{|l|}{ Age } \\
\hline Median, years & 63 & 54 & 71.5 \\
\hline Range, years & $43-73$ & $43-64$ & $65-73$ \\
\hline \multicolumn{4}{|l|}{ Gender, n (\%) } \\
\hline Male & $20(95.2)$ & $10(90.9)$ & $10(100)$ \\
\hline Female & I (4.8) & I (9.1) & 0 \\
\hline \multicolumn{4}{|l|}{ Karnofsky PS, n (\%) } \\
\hline 100 & $8(38.1)$ & $7(63.6)$ & $I(10)$ \\
\hline 90 & $7(33.3)$ & $3(27.3)$ & $4(40)$ \\
\hline 80 & $5(23.8)$ & I (9.1) & $4(40)$ \\
\hline 70 & I (4.7) & 0 & $I(10)$ \\
\hline \multicolumn{4}{|l|}{ Clinical tumor staging, n (\%) } \\
\hline TIbNOMO & $6(28.6)$ & I (9.1) & $5(50)$ \\
\hline T2NOMO & $12(57.1)$ & $8(72.7)$ & $4(40)$ \\
\hline TIbNIMO & I (4.7) & I (9.1) & 0 \\
\hline $\mathrm{T} 2 \mathrm{~N} 2 \mathrm{bM} 0$ & I (4.7) & 0 & $I(10)$ \\
\hline T3NOMO & I (4.7) & I (9.I) & 0 \\
\hline \multicolumn{4}{|l|}{ Surgical treatment, n (\%) } \\
\hline MSCL-CHEP & $19(90.5)$ & II (I00) & $8(80)$ \\
\hline MSCL-CHP & $2(9.52)$ & 0 & $2(20)$ \\
\hline $\begin{array}{l}\text { Monolateral selective } \\
\text { neck dissection, n (\%) }\end{array}$ & $2(9.52)$ & I (9.I) & $I(10)$ \\
\hline
\end{tabular}

Abbreviations: CHP, cricohyoidopexy; CHEP, cricohyoidoepiglottopexy; PS, performance score; MSCL, modified supracricoid laryngectomy. total laryngectomy). The mean decannulation time was $35.7 \pm 4.1$ days (younger group $34.2 \pm 4.5$ days; older group $37.6 \pm 2.6$ days; $P=0.07)$.

All patients were alive for the duration of the study, which had a median follow-up of $42.9 \pm 18$ months. Follow-up was $44.54 \pm 15.9$ months in patients younger than 65 years of age and $41.2 \pm 10.8$ months in patients older than 65 years of age. This difference was not statistically significant $(P=0.68)$.

None of the patients developed distant metastases or a second tumor during the study. There was a laryngeal recurrence 8 months after modified SCL in a patient older than 65 years who had previously received laser $\mathrm{CO}_{2}$ cordectomy. Total laryngectomy was performed as salvage surgery. One patient younger than 65 years of age developed an arytenoid recurrence with ipsilateral lymphadenopathy 2 years after modified SCL. He received total laryngectomy and monolateral selective neck dissection, and negative nodes were found during histological examination. No postoperative complications were reported in either patient.

The mean larynx preservation index for all patients was $90.1 \%$. Ten of the 11 patients younger than 65 years of age and nine of the 10 patients older than 65 years of age retained a normally functioning larynx, with indexes of $90.9 \%$ and $90 \%$, respectively. This difference was not statistically significant.

The actuarial overall survival rate and the actuarial disease-specific survival rate were $100 \%$ in each group of patients. Actuarial recurrence-free survival rate and laryngoesophageal dysfunction-free survival was $90.1 \%$ in the younger patient group and $90 \%$ in the older patient group $(P=0.91$, Figure 1$)$.

Vocal function was assessed using the INFVo scale. There were no statistically significant differences in intelligibility, fluency, and voicing between the two patient groups, but the sound of the voice was significantly worse in patients older than 65 years of age $(P=0.01)$. Patients younger than 65 years of age had good quality of voice (total value of INFVo 31.3) and patients older than 65 years of age had fair quality of voice (total value of INFVo 28). This difference was not statistically significant, probably due to the small number of patients in the study (Table 3).

The anterior commissure appeared to be involved in 13 cases at laryngoscopy, while histological examination confirmed clinical findings in six cases, including one with focal invasion of the thyroid cartilage perichondrium. This patient had a T2N0M0 glottic cancer, which was treated by modified SCL-CHEP, and had no locoregional recurrence 
Table 2 Postoperative outcomes, functional outcomes and follow-up period

\begin{tabular}{|c|c|c|c|c|}
\hline Parameter & $\begin{array}{l}\text { Patients } \\
(n=2 I)\end{array}$ & $\begin{array}{l}\text { Patients }<65 \text { years } \\
(n=I I)\end{array}$ & $\begin{array}{l}\text { Patients }>65 \text { years } \\
(n=10)\end{array}$ & $P$ value \\
\hline \multicolumn{5}{|c|}{ Length of hospitalization } \\
\hline Median (days) & 22 & 21 & 23 & $0.39 *$ \\
\hline Range (days) & $16-43$ & $16-38$ & $16-43$ & \\
\hline \multicolumn{5}{|c|}{ Nasogastric feeding tube removal } \\
\hline Median (days) & 19 & 19 & 18.5 & $0.85^{*}$ \\
\hline Range (days) & $14-36$ & $14-36$ & $14-28$ & \\
\hline \multicolumn{5}{|l|}{ Decannulation } \\
\hline $\mathrm{n}(\%)$ & $20(95.2)$ & II (100) & $9(90)$ & $0.47^{* *}$ \\
\hline \multicolumn{5}{|l|}{ Decannulation time } \\
\hline Median (months) & 8 & 8 & 10 & $0.12^{*}$ \\
\hline Range (months) & $4-36$ & $4-36$ & $6-24$ & \\
\hline \multicolumn{5}{|l|}{ Total laryngectomy } \\
\hline $\mathrm{n}(\%)$ & $2(9.5)$ & I (9) & $I(10)$ & $\mid * *$ \\
\hline \multicolumn{5}{|l|}{ Follow-up period } \\
\hline Median (months) & 31 & 31 & 32 & $0.48 *$ \\
\hline Range (months) & $10-72$ & $10-72$ & $11-72$ & \\
\hline
\end{tabular}

Notes: *Mann-Whitney test; **Fisher's Exact test.

at 5 years. This date confirms the oncological radicality and safety of modified SCL.

The histological examination differed from the clinical stage in nine cases; three tumors were underestimated (2cT1b and 1cT2 were pT3, pT2 and pT3, respectively), four tumors were overestimated (2cT2 was pT1a, 3cT2 was pT1b, and $1 \mathrm{cT} 1 \mathrm{~b}$ was pT1a) and the two patients with clinical pathological nodes who received monolateral selective neck dissection had negative nodes at histological examination.

\section{Discussion}

SCL is a validated technique of open organ preservation surgery for early glottic cancer. ${ }^{12}$ Several papers have reported on the oncological and functional outcomes of SCL. ${ }^{13-15}$ Modified SCL was introduced in our department as an SCL variant, ${ }^{6}$ and a previous report ${ }^{7,8}$ has demonstrated improvements in quality of voice and quality of life after modified SCL, compared with the original SCL technique. This paper validates oncological safety and reports the functional outcomes of this new technique.

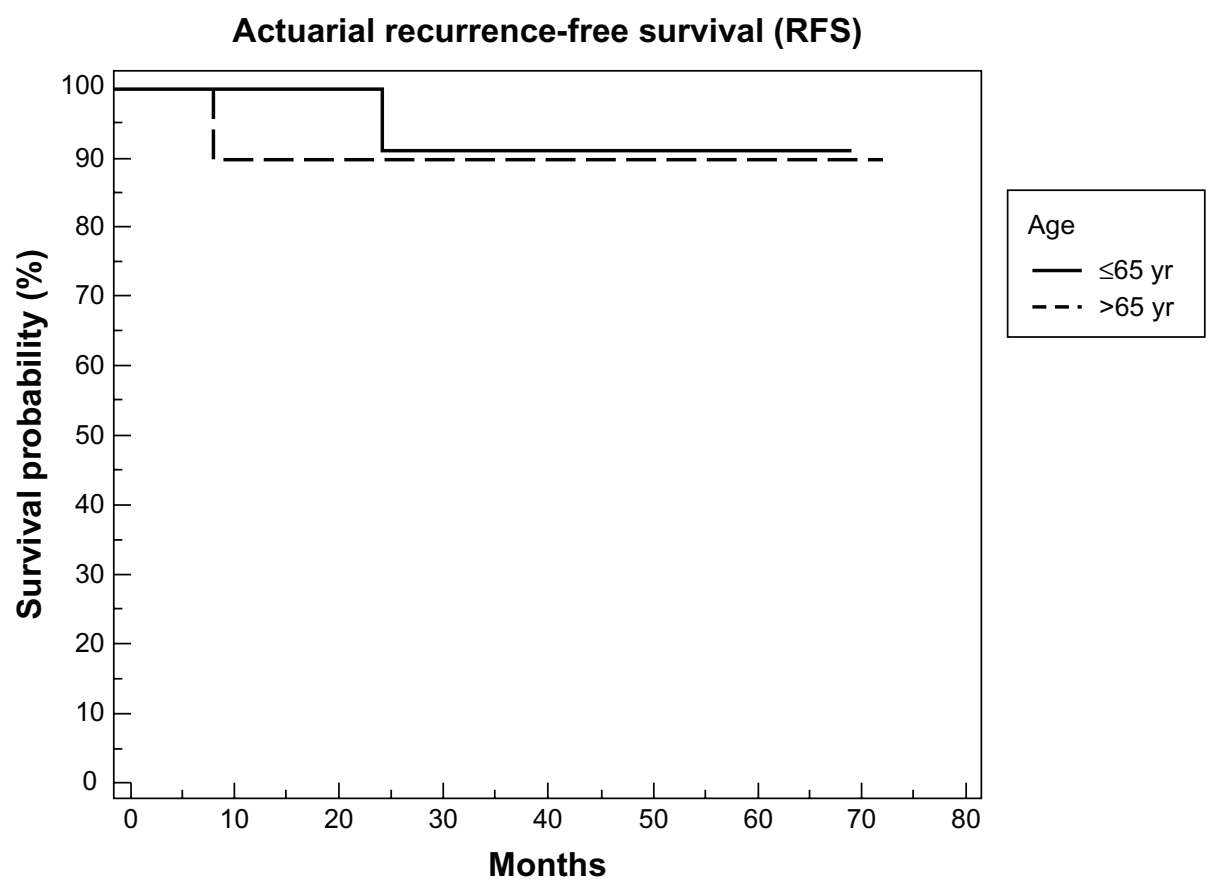

Figure I Recurrence-free survival rate.

Note: Comparison of recurrence-free survival rate in patients younger and older than 65 years of age. 
Table 3 INFVo rating scale

\begin{tabular}{lllll}
\hline Parameter & $\begin{array}{l}\text { Patients } \\
(\mathbf{n}=\mathbf{2} \mathbf{I})\end{array}$ & $\begin{array}{l}\text { Patients } \\
<\mathbf{6 5} \text { years } \\
(\mathbf{n}=\mathbf{I I})\end{array}$ & $\begin{array}{l}\text { Patients } \\
>\mathbf{6 5} \text { years } \\
(\mathbf{n}=\mathbf{1 0})\end{array}$ & P value* \\
\hline $\mathrm{I}$ & 7.7 & 8 & 7.5 & 0.77 \\
$\mathrm{~N}$ & 7 & 7.7 & 6.3 & 0.01 \\
$\mathrm{~F}$ & 7.5 & 7.7 & 7.4 & 0.30 \\
Vo & 6.5 & 7 & 6 & 0.39 \\
Total & 29.5 & 31.3 & 28 & 0.08 \\
\hline
\end{tabular}

Note: *Mann-Whitney test.

Abbreviations: I, intelligibility; N, noise; F, fluency; Vo, voicing.

According to a recent literature review, ${ }^{9}$ chronological age should not be considered a main contraindication to open partial laryngectomies, and elderly patients should be treated with curative intent. Our study applied modified SCL in well selected elderly patients (good performance status, preserved cardiorespiratory condition). No statistically significant differences between these patients' and younger patients' functional and oncological outcomes were found after modified SCL. Our data are similar to those reported in the literature. ${ }^{14}$

Selection criteria for SCL are important for functional and oncological outcomes. Vocal fold fixation is a main contraindication for modified SCL, because the preservation of both arytenoids is essential for the sternohyoid muscle flap anchorage to vocal processes.

Gallo et $\mathrm{a}^{13}$ demonstrated that the most important predictor of survival in patients undergoing SCL was recurrence, and in the pathological validations of SCL reported by Sun ${ }^{14}$ and Hartl et al, ${ }^{18}$ local recurrence was associated with positive resection margins and perilaryngeal soft tissue invasion. In our study, all surgical margins were negative. We also retrospectively reviewed the histopathological status of the thyroid cartilage and compared it with the clinical characteristics of the tumor. In modified SCL, the use of sternohyoid muscle flaps for neoglottis reconstruction can increase the risk of laryngeal recurrence, especially in patients with thyroid cartilage infiltration.

In our small sample, there was only one case of histological focal infiltration of thyroid cartilage. This was in a patient affected by T2N0M0 glottic cancer which involved the anterior commissure, and the whole left vocal fold had impaired mobility. Computed tomography did not identify thyroid cartilage invasion and patient underwent modified SCL-CHEP. This patient was alive and free from disease at the end of the study.

In our sample, there was a $9.5 \%$ rate of recurrence $(2 / 21)$ and the local control rate was $90.5 \%$. Our oncological results are similar to those reported in the literature, even though our sample was small. Gallo et $\mathrm{a}^{13}$ reported locoregional recurrence in $8.7 \%$ of 234 patients who underwent SCL with CHP or CHEP, Sanchez-Cuadrado et a ${ }^{15}$ reported locoregional recurrence in $25 \%$ of 41 patients treated by SCL with CHP or CHEP, Gonçalves et a ${ }^{16}$ reported locoregional recurrence in $5 \%$ of 20 patients treated by SCL, and Topaloğlu et $\mathrm{al}^{3}$ reported locoregional recurrence in $2.2 \%$ of 44 patients who underwent SCL with CHP. Furthermore, in our study, there were no distant metastases or second tumors, probably because of the restrictive selection criteria for modified SCL.

The functional outcomes of modified supracricoid laryngectomy were similar to those reported in the literature. The nasogastric feeding tube was removed after a mean of 19 days, which is a similar or shorter period than that reported in the literature (Gallo et a ${ }^{13}$ reported 19 days, SanchezCuadrado $^{14}$ reported 18 days, Topaloğlu et $\mathrm{al}^{3}$ reported 29.3 days, and Gonçalves et a $1^{16}$ reported 2.3 months). This outcome can be attributed to both arytenoid preservation and neoglottis reconstruction.

The decannulation rate was $90.5 \%$, which is similar to that reported in the literature (Gallo et a ${ }^{13}$ reported $92 \%$, SanchezCuadrado ${ }^{15}$ reported $97 \%$, and Topaloğlu et $\mathrm{al}^{3}$ reported $100 \%)$. All patients had a normal diet, and gastrostomy was not used (versus $2 \%$ reported in a literature review ${ }^{19}$ ).

Voice perceptive analysis showed good voice quality after modified SCL in both patient groups, and only the noise parameter was statistically worse in the older group. Our data analysis demonstrates the oncological safety of modified SCL and confirms the positive functional outcomes and quality of voice without any compliances as previously reported, ${ }^{7,8}$ which make this technique feasible in elderly patients.

\section{Conclusion}

Modified SCL is a new surgical technique for open organ preservation, which improves the quality of voice in patients with early glottic cancer. This report demonstrates the oncological radicality and safety of modified SCL. Moreover, modified SCL functional outcomes and improved quality of voice allow the application of this technique in selected elderly patients with no postoperative complications, brief rehabilitation, and rapid recovery. While strict selection criteria limit the use of modified SCL, they are essential for the correct performance of this new surgical technique and enable positive functional outcomes.

\section{Disclosure}

The authors report no conflicts of interest in this work. 


\section{References}

1. Hartl DM, Ferlito A, Brasnu DF, et al. Evidence-based review of treatment options for patients with glottic cancer. Otolaryngol Head Neck Surg. 2011;142:137-139.

2. Majer EH, Rieder W. Technique of laryngectomy permitting the conservation of respiratory permeability (cricohyoidopexy). Ann Otolaryngol. 1959;76:677-681. French.

3. Topaloğlu I, Bal M, Salturk Z. Supracricoid laryngectomy with cricohyoidopexy: oncological results. Eur Arch Otorhinolaryngol. 2012;269(8):1959-1965.

4. Makeieff M, Venegoni D, Mercante G, et al. Supracricoid partial laryngectomies after failure of radiation therapy. Laryngoscope. 2005;115:353-357.

5. De Virgilio A, Fusconi M, Gallo A, et al. The oncologic radicality of supracricoid partial laryngectomy with cricohyoidopexy in the treatment of advanced N0-N1 laryngeal squamous cell carcinoma. Laryngoscope. 2012;122:826-833.

6. Garozzo A, Allegra E, La Boria A, et al. Modified supracricoid laryngectomy. Otolaryngol Head Neck Surg. 2010;142:137-139.

7. Allegra E, Lombardo N, La Boria A, et al. Quality of voice evaluation in patients treated by modified supracricoid laryngectomy. Otolaryngol Head Neck Surg. 2011;145:789-795.

8. Allegra E, Trapasso S, Franco T, Aragona T, Domanico R, Garozzo A. Quality of life in patients treated by organ preservation surgery for early laryngeal carcinoma. Open Access Surgery. 2012;5:1-6.

9. Reizenstein JA, Bergstrom SN, Holmberg L, et al. Impact of age at diagnosis on prognosis and treatment in laryngeal cancer. Otolaryngol Head Neck Surg. 2010;32:1062-1068.

10. Sobin LH, Gospodarowicz MK, Wittekind C. TNM Classification of Malignant Tumours, 7th ed. Oxford, UK: Wiley-Blackwell; 2009.
11. Moerman M, Martens JP, Crevier-Buchman L, et al. The INFVo Perceptual Rating Scale for Substitution Voicing: development and reliability. Eur Arch Otorhinolaryngol. 2006;263:435-439.

12. Pfister DG, Laurie SA, Weinstein GS, et al. American Society of Clinical Oncology clinical practice guideline for the use of larynxpreservation strategies in the treatment of laryngeal cancer. $J$ Clin Oncol. 2006;24:3693-3704.

13. Gallo A, Manciocco M, Simonelli M, et al. Supracricoid partial laryngectomy in the treatment of laryngeal cancer. Arch Otolaryngol Head Neck Surg. 2005;131:620-625.

14. Sun DI, Cho KJ, Joo YH, et al. Pathological validation of supracricoid partial laryngectomy in laryngeal cancer. Clin Otolaryngol. 2009;34:132-139.

15. Sanchez-Cuadrado I, Castro A, Bernàldez R, et al. Oncological outcomes after supracricoid partial laryngectomy. Otolaryngol Head Neck Surg. 2011;144:910-914.

16. Gonçalves AJ, Bertelli AAT, Malavasi TR, et al. Results after supracricoid laryngectomy. Auris Nasus Larynx. 2010;37:84-88.

17. Lefebvre JL, Ang KK; Larynx Preservation Consensus Panel. Larynx preservation clinical trial design: key issues and recommendations a consensus panel summary. Head Neck. 2009;31(4):429-441.

18. Hartl DM, Landry G, Hans S, et al. Organ preservation surgery for laryngeal squamous cell carcinoma: low incidence of thyroid cartilage invasion. Laryngoscope. 2010;120:1173-1176.

19. Paleri V, Thomas L, Drinnan M, et al. Open conservation partial laryngectomy for laryngeal cancer: a systematic review of English language literature. Cancer Treat Rev. 2012;38:203-211.
Clinical Interventions in Aging

\section{Publish your work in this journal}

Clinical Interventions in Aging is an international, peer-reviewed journal focusing on evidence-based reports on the value or lack thereof of treatments intended to prevent or delay the onset of maladaptive correlates of aging in human beings. This journal is indexed on PubMed Central, MedLine, the American Chemical Society's 'Chemical Abstracts Ser-

\section{Dovepress}

vice' (CAS), Scopus and the Elsevier Bibliographic databases. The manuscript management system is completely online and includes a very quick and fair peer-review system, which is all easy to use. Visit $\mathrm{http}: / /$ www.dovepress.com/testimonials.php to read real quotes from published authors. 